\title{
Effect of duration of melatonin treatment on the onset and duration of oestrous cyclicity in ewes
}

\author{
J. J. Robinson, J. M. Wallace, R. P. Aitken and S. Wigzell \\ The Rowett Research Institute, Bucksburn, Aberdeen AB2 9SB, UK
}

\begin{abstract}
Summary. Forty-two Scottish Blackface ewes that lambed outdoors in March were removed from their lambs at the end of April and housed under natural daylength at $57^{\circ} \mathrm{N}$. Treatments ( $n=7$ ewes per treatment) commenced on 1 May and comprised daily oral dosing at $15: 00 \mathrm{~h}$ with $3 \mathrm{mg}$ melatonin dissolved in water and ethanol (4:1, $\mathrm{v} / \mathrm{v}$ ) for $30,60,90,120$ or 150 days. Control ewes received the vehicle alone. Ovarian activity was assessed by laparoscopy at monthly intervals with an additional interim observation in mid-July. Blood was sampled three times a week by jugular venepuncture and assayed for progesterone, prolactin and follicle-stimulating hormone (FSH). Luteinizing hormone ( $\mathrm{LH})$ was determined in blood samples collected at $15 \mathrm{~min}$ intervals for $10 \mathrm{~h}$ on days $28,60,91,119$ and 150 .

Thirty days of melatonin treatment delayed $(P<0.01)$ first ovulation by about 1 month (mean interval \pm SEM from 1 May to progesterone $>1 \mathrm{ng} \mathrm{m}^{-1}, 165 \pm 4.5$ days versus $132 \pm 9 \cdot 2$ days for controls). None of the ewes that received melatonin for 60 days ovulated before the end of melatonin treatment, but subsequently six of them did; the mean interval from 1 May to increased progesterone concentration was $75 \pm 1 \cdot 2$ days. All ewes receiving melatonin for 90,120 and 150 days ovulated with corresponding mean intervals of $83 \pm 2 \cdot 7,85 \pm 1 \cdot 3$ and $87 \pm 2.2$ days, respectively $(P<0.001$ compared with controls). Ewes treated for 60,90 and 120 days returned to anoestrus 4 6 weeks after the end of melatonin treatment; for the 120 day treatment this coincided with the onset of oestrous cyclicity in control ewes.

Melatonin had no effect on the concentrations of FSH. Thirty days of melatonin treatment in May delayed the autumn decline in LH pulse amplitude and increase in pulse frequency, whereas treatment for 120 and 150 days advanced these changes to late July-early August. Prolactin concentrations declined to minimum values after 30 days of melatonin treatment, but began to increase again after about 100 days. After the treatments for 90,120 and 150 days, prolactin increased to higher concentrations $(P<0.001)$ than in controls and failed to return to control values before sampling ended in late October, i.e. 95,65 and 35 days later, respectively.
\end{abstract}

Keywords: melatonin; ovulation; luteinizing hormone; prolactin; ewe

\section{Introduction}

Numerous studies have demonstrated the success of exogenously administered melatonin in mimicking the stimulatory effect of short days on the initiation of ovarian activity in ewes (see e.g. Arendt et al., 1988; Kennaway, 1988; Poulton, 1988). In these studies, the methods of administration of melatonin ranged from continuous slow-release formulations to fixed time daily dosing or feeding. When the oral route is used, melatonin must be administered every day to be effective (Ronayne et al., 1989). It is not surprising, therefore, that a slow-release implant is an attractive practical alternative (Haresign et al., 1990). However, there is now evidence to suggest that the 
magnitude of the advance in the breeding season that can be achieved by a slow-release implant is considerably less than that for daily administration. For example, the insertion of melatonin implants in ewes in mid-May in Britain was ineffective in advancing the breeding season (Nowak \& Rodway, 1985), yet daily oral dosing with $3 \mathrm{mg}$ melatonin at 15:00 h from 5 March (Wigzell et al., 1986) or 22 March (Wallace et al., 1988) resulted in behavioural oestrus in late May-early June, 4 months before that of untreated control ewes.

Unless melatonin is administered by a method that stimulates a marked advance of the breeding season, it may offer little benefit over alternative stimulatory techniques such as the progestagen pessary (Rajkumar et al., 1989; Crosby \& O'Callaghan, 1991) or carefully timed exposure to the ram (Robinson et al., 1991). At present the only method of administering melatonin that ensures a marked advance of the breeding season in ewes is via daily oral intake in mid-afternoon (Robinson et al., 1992), but application in this way raises important questions about the effects of duration of treatment on the timing and duration of oestrous cyclicity.

In this study we report the results of an experiment in which a highly seasonal breed of ewe was maintained under the ambient photoperiod at $57^{\circ} \mathrm{N}$ and given daily, at 15:00 h, an oral dose of melatonin from 1 May. Durations of treatment were 30,60, 90, 120 and 150 days. A diverse range of effects on the endocrinology and ovarian activity of the ewes was observed.

\title{
Materials and Methods
}

\begin{abstract}
Animals
Forty-two Scottish Blackface ewes that lambed outdoors at the Rowett Research Institute, Aberdeen, in March were abruptly weaned from their lambs at the end of April 1987, brought indoors and housed until mid-November under natural daylength conditions at $57^{\circ} \mathrm{N}$. Their mean bodyweight on coming indoors was $63 \mathrm{~kg}$ and each ewe was given an individual pen in the same building. Throughout the experiment each ewe received daily, in two equal feeds, at $08: 00 \mathrm{~h}$ and $16: 00 \mathrm{~h}$, a total of $1.4 \mathrm{~kg}$ of a complete diet containing $9 \mathrm{MJ}$ of metabolizable energy and $125 \mathrm{~g}$ crude protein $\mathrm{kg}^{-1}$. The ewes were allocated to six groups of similar weight and the location of ewes from each group occurred at random throughout the building. Treatments commenced on 1 May (day 0 ) and for five of the groups consisted of daily oral dosing of each ewe at 15:00 h with $3 \mathrm{mg}$ of melatonin (Sigma Chemical Co., Poole, Dorset, UK) dissolved in a 4:1 mixture of water and ethanol for 30,60,90,120 and 150 days. The remaining group acted as controls and received vehicle alone. All ewes were sheared on $25 \mathrm{May}$ and their ovaries were examined by laparoscopy on the following dates: 1 June, 2 July, 17 July, 5 August, 3 September, 1 October and 9 November, 1987.

Blood samples $(5 \mathrm{ml}$ ) were taken three times a week (Monday, Wednesday and Friday) from each ewe by jugular venepuncture and the plasma was assayed for progesterone, prolactin and follicle-stimulating hormone (FSH); $2 \mathrm{ml}$ blood samples were taken from an indwelling jugular vein catheter (Braunula, 14 G; Dunlop Veterinary Supplies, Dumfries, UK) for $10 \mathrm{~h}(08: 00$ to $18: 00 \mathrm{~h})$ at intervals of $15 \mathrm{~min}$ on days $28,60,91,119$ and 150 of the experiment and the samples were analysed for luteinizing hormone ( $\mathrm{LH})$.
\end{abstract}

\section{Hormone assays}

Progesterone concentrations were measured in $100 \mu \mathrm{l}$ aliquots of plasma by radioimmunoassay as described by Djahanbakhch et al. (1981). The lower limit of detection was $0.3 \mathrm{ng} \mathrm{ml}^{-1}$ and the intra- and interassay coefficients of variation were $11 \cdot 2$ and $8 \cdot 1 \%$, respectively. The recovery of progesterone from plasma was $64 \cdot 7 \pm 1 \cdot 2 \%(n=3283)$ and the results are corrected individually. Concentrations of LH and prolactin were measured in duplicate by specific double-antibody radioimmunoassay as described by McNeilly et al. (1986) and McNeilly \& Andrews (1974). The sensitivities of the assays were $0.05 \mathrm{ng} \mathrm{LH}$ (NIADDK-oLH-25) ml ${ }^{-1}$ and $0.08 \mathrm{ng}$ prolactin (NIADDK-oPRL-17) $\mathrm{ml}^{-1}$. The intra- and interassay coefficients of variation were $5 \cdot 3$ and $8 \cdot 2 \%$ for LH and 5.0 and $9 \cdot 6 \%$ for prolactin, respectively. FSH concentrations were measured in duplicate by the method of McNeilly et al. (1976). The sensitivity of the assay was $0.08 \mathrm{ng}$ FSH (NIAMDD-oFSH-RPI) $\mathrm{ml}^{-1}$ and the intra- and interassay coefficients of variation were $5 \cdot 1$ and $8 \cdot 6 \%$, respectively.

\section{Definitions and statistical analysis}

An increase in LH was assumed to be a pulse if the concentration for two consecutive samples was greater than the mean of the two previous samples (basal concentration) and the concentration of at least one of the pulse samples exceeded the mean basal concentration by more than four times the intra-assay coefficient of variation of the assay (after Backstrom et al., 1982). 
For each ewe, the day when the first of three consecutive blood samples in the sampling routine of three times a week had $>$ I ng progesterone $\mathrm{ml}^{-1}$ was taken as the onset of ovarian activity.

The statistical significance of treatment effects on the onset of ovarian cyclicity, ovulation rates and the various measures of endocrine status were tested by analysis of variance.

\section{Results}

\section{Ovarian activity}

None of the 42 ewes had corpora lutea on their ovaries at laparoscopy on 1 June and 2 July although before the first laparoscopy on 1 June one control ewe and one ewe from each of the 120- and 150-day melatonin treatments exhibited a transitory increase in plasma progesterone concentration (Fig. 1), which indicated the occurrence of isolated ovulations. At laparoscopy on 17 July all control ewes and those that received melatonin for 30 days had not ovulated. This observation was confirmed by their plasma progesterone concentrations (see Fig. 1). Of the seven ewes receiving melatonin for 60 days, five had corpora lutea at laparoscopy on both 17 July and 5 August, i.e. 18 and 37 days, respectively, after the end of melatonin treatment and six showed high progesterone concentrations at a mean ( \pm SEM) interval from 1 May of $75 \pm 1 \cdot 2$ days. Corresponding intervals for the 90,120 and 150 day treatments in which all ewes had high progesterone concentrations were $83 \pm 2 \cdot 7,85 \pm 1 \cdot 3$ and $87 \pm 2 \cdot 2$ days, respectively. These intervals contrast $(P<0.001)$ with a mean of 132 (10 September $\pm 9 \cdot 2$ ) days for the seven control ewes. A period of 30 days of melatonin treatment starting on 1 May delayed the onset of ovarian activity by a further 33 days compared with control ewes $(P<0.01)$ resulting in a mean interval of 165 (13 October \pm 4.5 ) days.

For ewes receiving melatonin for 60,90 and 120 days the duration of oestrous cyclicity was shortened (see Fig. 1). The ewes returned to anoestrus 4 to 6 weeks after the termination of melatonin treatment and at times that corresponded to the normal period of oestrous cyclicity in control ewes. There was a suggestion from the progesterone profile data that ewes receiving melatonin for 150 days, i.e. up to the end of September, also returned to anoestrus before the end of the breeding season of the control ewes. This was confirmed by laparoscopic observations that showed that only one of the seven ewes on the 150 day melatonin treatment had corpora lutea on 9 November. Indeed the progesterone profile data indicated that anoestrus had already occurred in some ewes on this treatment either before or towards the end of the period of exposure to exogenous melatonin (see Fig. 1).

At the time of first ovulation, ewes in the 90,120 and I50 day melatonin-treatment groups were receiving melatonin. Their mean ovulation rate ( \pm SEM), when first detected by laparoscopy to have ovulated, was $1.9 \pm 0.19(n=18)$. In contrast, ewes in the other three groups were not receiving melatonin at the time of first ovulation and had a lower, albeit not statistically significant, mean ovulation rate of $1 \cdot 6 \pm 0 \cdot 12(n=21)$.

\section{Endocrine data}

\section{Prolactin}

For all groups, prolactin concentrations were initially high and declined as the ewes adjusted to the removal of their lambs and became accustomed to the routine of blood sampling (Fig. 2). The decline was more pronounced in those receiving melatonin than in controls, the mean concentrations on day 24 being $120 \pm 30 \mathrm{ng} \mathrm{ml}^{-1}$ for controls and $46 \pm 6.3 \mathrm{ng} \mathrm{ml}^{-1}$ for those receiving melatonin $(P<0.001)$. After the removal of the fleece on day 25 , prolactin concentrations immediately fell $(P<0 \cdot 001)$ to $31 \pm 8.8$ and $15 \pm 5 \cdot 1 \mathrm{ng} \mathrm{ml}^{-1}$ for control and treated ewes, respectively. In general, minimum prolactin concentrations were achieved after 30 days of melatonin treatment, but these low concentrations were not sustained indefinitely in that ewes receiving melatonin for 120 and 150 days began to exhibit high concentrations after about 100 days of treatment (see Fig. 2).

Comparison of the prolactin profiles in the period after melatonin withdrawal with those exhibited by control ewes reveals some interesting effects. Termination of melatonin treatment after 30 days gave rise to a post-treatment prolactin profile that was very similar to that observed in 


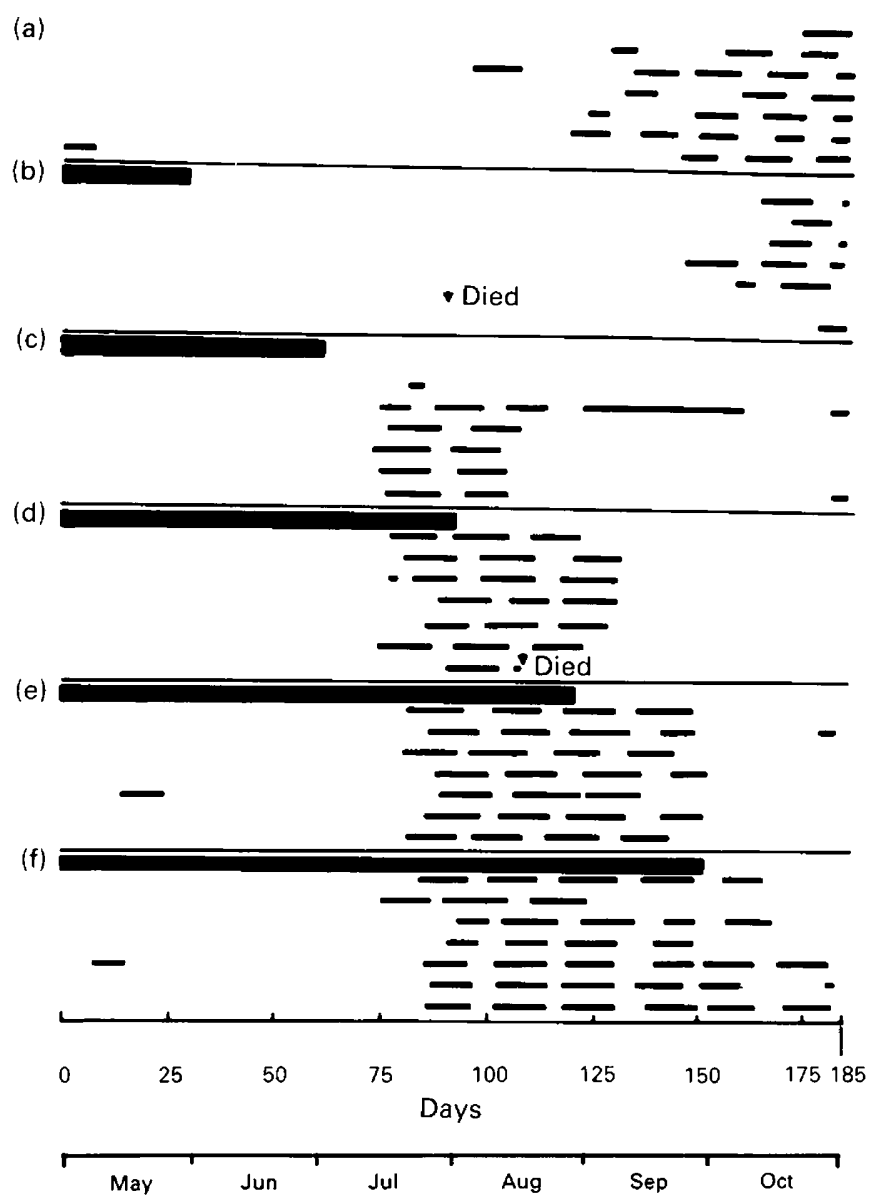

Fig. 1. Ovarian activity in Scottish Blackface ewes kept under natural photoperiod at $57^{\circ} \mathrm{N}$ and given daily, at 15:00 h, an oral dose of $3 \mathrm{mg}$ melatonin for (b) 30, (c) 60, (d) 90 , (e) 120 or (f) 150 days ( $\mathbf{a})$ from 1 May. Controls (a) received the vehicle alone. $(\longrightarrow$ ) periods over which the plasma progesterone was $>1 \mathrm{ng} \mathrm{ml}^{-1}$, indicating the presence of a corpus luteum.

untreated control ewes. In contrast, durations of melatonin treatment of 60,90 or 120 days were followed, after the termination of treatment, by significant $(P<0.001)$ increases in prolactin to concentrations that were equal to or higher than those of controls over the same period. After treatment for 150 days there was no significant increase in prolactin but concentrations remained higher than those for the control ewes. For the 90 and 120 day treatments concentrations also remained, in the post-treatment period, significantly higher $(P<0.001)$ than those observed for controls at this time.

\section{Follicle-stimulating hormone}

Plots (not shown) for the concentrations of FSH revealed no consistent trends that could be attributed to melatonin. Treatment mean concentrations ( \pm SEM) following 30,60,90, 120 and 150 days of melatonin were $3.9 \pm 0.34,3.8 \pm 0.22,4.1 \pm 0.22,3.7 \pm 0.18$ and $4.1 \pm 0.58 \mathrm{ng} \mathrm{ml}^{-1}$, respectively. Over the same period there was no significant change in FSH concentrations for controls, the mean values after 30 and 150 days being $4.1 \pm 0.32$ and $4.2 \pm 0.48 \mathrm{ng} \mathrm{ml}^{-1}$, respectively. 
(a)

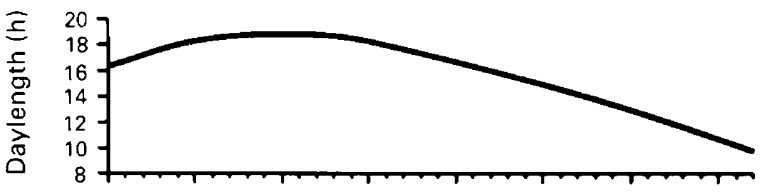

(b)

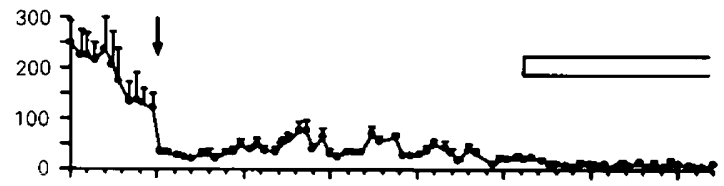

(c)

(d)

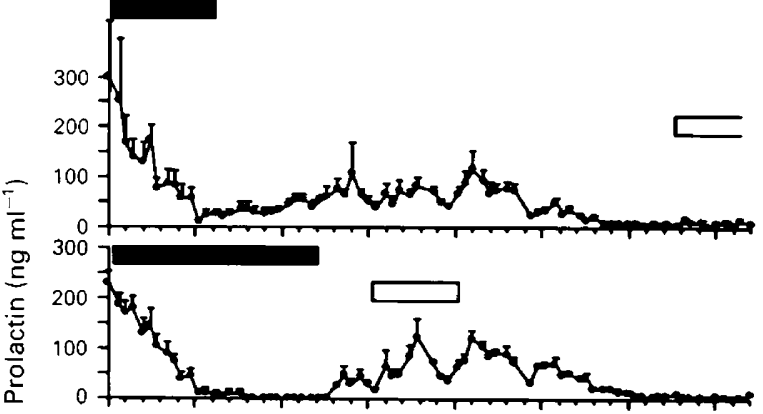

(e)

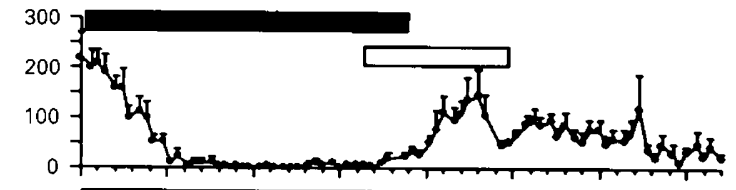

(f)

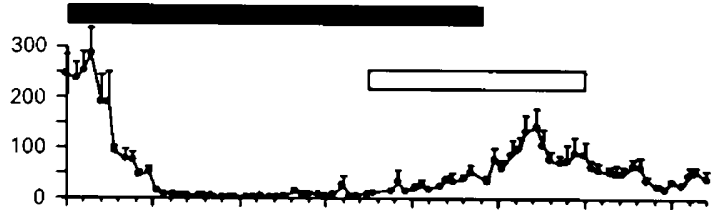

(g)

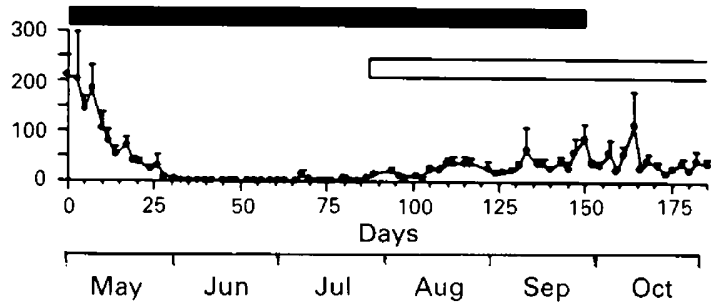

Fig. 2. Prolactin concentrations for Scottish Blackface ewes kept under natural photoperiod (a) at $57^{\circ} \mathrm{N}$ and given daily at 15:00 h, an oral dose of $3 \mathrm{mg}$ melatonin for (c) 30 , (d) 60 , (e) 90 , (f) 120 or (g) 150 days ( $\mathbf{D}$ ) from 1 May. Controls (b) received the vehicle alone. Values are means $\pm \mathrm{SEM}, n=7$ per treatment; $(\square)$ average duration of ovarian activity based on increased progesterone concentrations; $\downarrow$ shearing.

\section{Luteinizing hormone}

Blood samples taken from all ewes at 15 min intervals for $10 \mathrm{~h}(08: 00$ to 18:00 h) on days 28, 60, 91,119 and 150 of the experiment provided the basis of testing temporal and treatment effects on the amplitude and frequency of the episodic release of $\mathrm{LH}$. The data from these observations are given, against the background of the onset of ovarian activity (progesterone $>1 \mathrm{ng} \mathrm{ml}^{-1}$ for three consecutive samples) (Fig. 3). In general the amplitude of the LH pulses decreased and their frequency increased as the ewes entered either natural (control) or melatonin-induced breeding 
activity (see Fig. 3). This inverse relationship between pulse amplitude and frequency was most pronounced in ewes receiving melatonin for 120 and 150 days. Here the coefficients of correlation between amplitude and frequency were -0.91 and $-0.88(P<0.05)$ for the 120 and 150 day treatments, respectively. For those receiving melatonin for 60 and 90 days the duration of oestrous cyclicity was reduced and although this was accompanied by a temporary decline $(P<0 \cdot 01)$, in pulse amplitude no corresponding increase in pulse frequency was detected. Compared with untreated controls, 30 days of treatment with melatonin in May delayed the autumn decline in $\mathbf{L H}$ pulse amplitude and increase in LH pulse frequency in line with the delay $(P<0.01)$ in the onset of oestrous cyclicity.

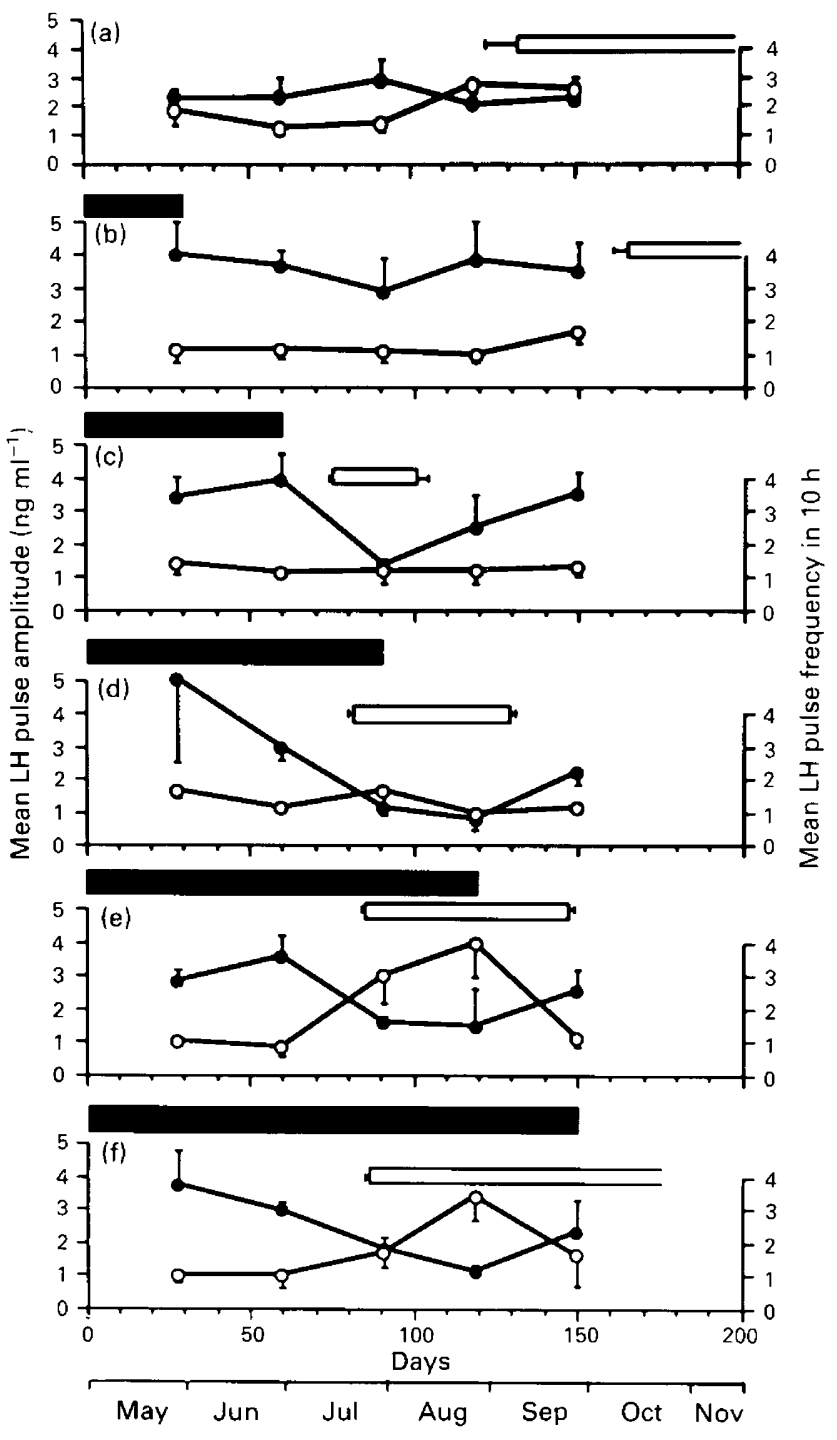

Fig. 3. Mean ( \pm SEM) values for luteinizing hormone $(\mathrm{LH})$ pulse amplitude $(\bullet)$ and frequency $(O)$ in Scottish Blackface ewes kept under natural photoperiod at $57^{\circ} \mathrm{N}$ and given daily at 15:00 h, an oral dose of $3 \mathrm{mg}$ of melatonin for (b) 30, (c) 60 , (d) 90 , (e) 120 or (f) 150 days (a) from 1 May. Controls (a) received the vehicle alone; $(\square)$ average duration, with SEM for ovarian activity based on increased progesterone concentrations. $n=7$ per treatment. 


\section{Discussion}

In this study ewes were isolated from rams and their ovarian activity was monitored by a combination of laparoscopy to view the ovaries and determination of progesterone concentrations three times a week to confirm the presence of corpora lutea. The observations on the onset and duration of oestrous cyclicity are therefore free from the stimulatory influence of the male (Martin et al., 1986) and as such provide a true assessment of the specific effects of melatonin.

One of the most interesting findings in the present study is the delay, by 33 days, in the normal onset of ovarian activity caused by daily oral doses of melatonin at 15:00 h for a period of 30 days starting on 1 May. This result is interesting for two reasons. First, for those promoting the practical application of melatonin, it demonstrates that a period of melatonin treatment that is inadequate to initiate oestrous cyclicity can have a counter-productive effect by delaying the normal breeding season. Second, it illustrates the long-term nature and complexity of the timing mechanism involved when an alteration in the circadian melatonin rhythm is used to reprogramme the neuroendocrine changes that induce oestrous cyclicity. Since the 30-day melatonin treatment terminated three weeks before the summer solstice, it seemed reasonable to assume that the ewes would have had ample time to readjust to long days and that the subsequent natural decline in daylength would have stimulated an onset to the breeding season that was coincident with that of the controls. This was not the case. It would therefore appear that the 30 day treatment with melatonin initiated changes within the ewes that clearly would have stimulated an advance of their breeding season, if the period of melatonin treatment had been extended (see 60, 90, 120 and 150 day treatments in Fig. 1). Apparently these changes were not immediately cancelled by the return of the ewes to the long-day ambient photoperiod when melatonin treatment ceased at the end of May. This was certainly the case for ewes receiving melatonin for 60 days in that the expression of the effects of melatonin, namely the onset of ovarian activity (progesterone $>1 \mathrm{ng} \mathrm{ml}{ }^{-1}$ ), did not occur until two weeks after the termination of melatonin treatment. Thus, having been programmed to occur by the 60-day period of melatonin treatment, ovarian activity, although restricted in its duration, was not prevented by the abrupt change from the short-day ( $11 \mathrm{~h}$ ) melatonin signal to the long-day $(18.5 \mathrm{~h})$ ambient photoperiod. Previous reports of a melatonin-induced advance of oestrous cyclicity that is delayed until after melatonin is withdrawn have either involved melatonin treatment that commenced after the summer solstice and therefore close to the natural breeding season (Nowak \& Rodway, 1987) or included the additional stimulatory influence of the ram (Kouimtzis et al., 1989).

After their transitory period of oestrous cyclicity during July and August, the magnitude of the delay beyond the controls in the resumption of oestrous cyclicity by the ewes receiving melatonin for 60 days was approximately equal to their period of melatonin treatment. This is based on the observation that at the final laparoscopy on 9 November (60 days after the onset of ovarian activity in controls) four of the seven ewes on this treatment had re-emerged from anoestrus. This contrasts with only one ewe in the 90-day group and none in the 120-day group.

Another interesting feature of the present data relates to the fact that a melatonin-induced period of oestrous cyclicity that overlaps with the natural onset of the breeding season (see Fig. 1 for the 90 and 120 days groups versus the controls) does not lead to a natural 'seasonally driven' continuation of oestrous cyclicity when melatonin is withdrawn. Indeed the intervals from the termination of melatonin treatment to the cessation of oestrous cyclicity were similar for the 60,90 and 120 day treatments. This indicates that the treatment differences in the ambient photoperiod in the period after melatonin withdrawal could not exert a discernible modifying influence on the inhibitory long-day signal generated by the termination of melatonin treatment.

The time lag in the ovarian response to photoperiod is assumed to represent the processing of the melatonin signal (Bittman et al., 1983) and some progress is now being made in understanding the molecular mechanisms involved. High-affinity receptors for melatonin have been identified in the pars tuberalis of the pituitary (Morgan \& Williams, 1989). These are membrane bound and are 
linked through an inhibitory $G$ protein to the inhibition of adenylyl cyclase (Morgan et al., 1990). The melatonin-responsive cell type in the pars tuberalis is secretory implying that an unidentified product secreted from the pars tuberalis may enable it to act as a relay in the neuroendocrine control of seasonal breeding (Morgan et al., 1991). However, up to now the timing of events in the neuroendocrine programming of the melatonin signal has not been readily detected in the form of uniform temporal shifts in hormone concentrations in the peripheral circulation. For example, the failure in the present experiment to detect any progressive increase in FSH concentrations over the period of melatonin treatment is in agreement with the observation of Poulton et al. (1987). Likewise progressive alterations in the amplitude and frequency of LH pulses have not been readily detected (Poulton et al., 1987; Ronayne et al., 1989). Nevertheless, in the present experiment the diverse nature of the treatment effects on the timing and duration of oestrous cyclicity provide interesting trends in LH pulse amplitude and frequency. For example, the delay in the onset of the breeding season caused by 30 days of melatonin treatment was reflected in an extended period of high-amplitude, low-frequency pulsing characteristic of anoestrus (Fig. 3). Longer periods of melatonin treatment ( 60 and 90 days), leading to an advance of the breeding season, followed by a shortened period of oestrous cyclicity and return to anoestrus coincident with the normal breeding season, were reflected in a transitory decline in pulse amplitude. Even longer periods (120 and 150 days), which promoted a more sustained period of oestrous cyclicity, were accompanied by a decline in amplitude and increase in frequency similar to that observed by L'Anson \& Legan (1988) just before the first rise in progesterone in ewes entering their natural breeding season. In the case of the 120 day treatment both amplitude and frequency reverted to the anoestrous pattern coincident with the ending of oestrous cyclicity (progesterone remaining $<1 \mathrm{ng} \mathrm{ml}^{-1}$ ) in late September, i.e. one month after melatonin withdrawal. Interestingly, at the same time a similar reversal occurred in the 150 day treatment group. This implies that refractoriness to the inductive exogenous melatonin signal in our ovary-intact ewes was occurring after an interval from the start of treatment that is very similar to that observed by Karsch et al. (1988) for LH to fall to undetectable levels in melatonin-infused ovariectomized ewes implanted with oestradiol.

The ability of melatonin to suppress prolactin is well known (Symons et al., 1983), so too is shearing (Rodway et al., 1983). However, the inability of long-term melatonin treatment to maintain the concomitant long-term suppression of prolactin suggests that the prolactin rise reflects the onset of refractoriness. The data reported here also add another example to those of Lincoln (1990) refuting the idea that the suppression of prolactin initiates the onset of the breeding season in that the initiation of ovarian activity in the 60 day treatment group occurred when prolactin concentrations were rising; for the 90 and 120 day treatments ovarian activity overlapped with some of the highest concentrations of prolactin recorded from June to October. These observations do not however preclude a role for the preceding period of prolactin suppression in the programming of the melatonin signal. Similarly, the progressive delay in onset of peak prolactin concentrations caused by increasing the duration of melatonin treatment and the subsequent time lag in the entrainment of prolactin to the ambient photoperiod after melatonin withdrawal (Fig. 2) may be essential features of the programming of the inhibition and subsequent induction of ovarian activity.

We thank M. Cheyne, I. Robertson and S. Wensvoort for skilled technical assistance and the NIADDK, L. E. Reichert and A. S. McNeilly for hormone preparations and antiserum. S. Wigzell was in receipt of an AFRC postgraduate scholarship.

\section{References}

Arendt, J., Symons, A.M., English, J., Poulton, A.L. \& Tobler, I. (1988) How does melatonin control seasonal reproductive cycles? Reproduction Nutrition Développement 28, 387-397.
Backstrom, C.T., McNeilly, A.S., Leask, R.M. \& Baird, D.T. (1982) Pulsatile secretion of LH, FSH, prolactin, oestradiol and progesterone during the menstrual cycle. Clinical Endocinology 17, 29.42. 
Bittman, E.L., Dempsey, R.J. \& Karsch, F.J. (1983) Pineal melatonin secretion drives the reproductive response to daylength in the ewe. Endocrinology 113 , 2276-2283.

Crosby, T.F. \& O'Callaghan, D. (1991) Effect of rumen degradable bolus containing melatonin or progesterone pessary plus pregnant mare serum gonadotropin on estrus response and lambing rate in ewes. Theriogenology 35, 747.752.

Djahanbakhch, O., Swanston, I.A., Corrie, J.E.T. \& McNeilly, A.S. (1981) Prediction of ovulation by progesterone. Lancet ii, 1164-1165.

Haresign, W., Peters, A.R. \& Staples, L.D. (1990) The effect of melatonin implants on breeding activity and litter size in commercial sheep flocks in the UK. Animal Production 50, 111-121.

Karsch, F.J., Malpaux, B., Wayne, N.L. \& Robinson, J.E. (1988) Characteristics of the melatonin signal that provide the photoperiodic code for timing seasonal reproduction in the ewe. Reproduction Nutrition Developpement 28, 459-472.

Kennaway, D.J. (1988) Short- and long-term effects of manipulation of the pineal/melatonin axis in ewes. Reproduction Nutrition Développement 28, 399-408.

Kouimtzis, S.A., Belibasaki, S. \& Doney, J.M. (1989) Melatonin advances and condenses the onset of scasonal breeding in Greek dairy ewes. Animal Production 48, 399-405.

L'Anson, H. \& Legan, S.J. (1988) Changes in LH pulse frequency and serum progesterone concentrations during the transition to breeding season in ewes. Journal of Reproduction and Ferlility 82, 341 351 .

Lincoln, G.A. (1990) Correlation with changes in horns and pelage, but not reproduction, of seasonal cycles in the secretion of prolactin in rams of wild, feral and domesticated breeds of sheep. Journal of Reproduction and Fertility 90, 285-296.

McNeilly, A.S. \& Andrews, P. (1974) Purification and characterization of caprine prolactin. Journal of Endocrinology 60, 359-367.

McNeilly, A.S., Jonansen, J.A. \& Frazer, H.M. (1986) Suppression of follicular development after chronic LHRH immunoneutralization in the ewe. Journal of Reproduction and Fertility 76, 481-490.

McNeilly, J.R., McNeilly, A.S., Walton, J.S. \& Cunningham, F.J. (1976) Development and application of a heterologous radioimmunoassay for ovine follicle-stimulating hormone. Journal of Endocrinology 70, 69-79.

Martin, G.B., Oldham, C.M., Cognie, Y. \& Pearce, D.T. (1986) The physiological responses of anovulatory ewes to the introduction of rams - a review. Livestock Production Science 15, 219-247.

Morgan, P.J. \& Williams, L.M. (1989) Central melatonin receptors: implications for a mode of action. Experientia 45, 955-965.

Morgan, P.J., Davidson, G., Lawson, W. \& Barrett, P. (1990) Both pertussis toxin-sensitive and insensitive $\mathrm{G}$-proteins link melatonin receptor to inhibition of adenylate cyclase in the ovine pars tuberalis. Journal of Neuroendocrinology 2, 773-776.

Morgan, P.J., King, T.P., Lawson, W., Slater, D. \& Davidson, G. (1991) Ultrastructure of melatoninresponsive cells in the ovine pars tuberalis. Cell and Tissue Research 263, 529534.

Nowak, R \& Rodway, R.G. (1985) Effect of intravaginal implants of melatonin on the onset of ovarian activity in adult and prepubertal ewes. Journal of Reproduction and Fertility 74, 287-293.

Nowak, R. \& Rodway, R.G. (1987) Length of melatonin exposure and onset of ovarian activity in anoestrous ewes. Journal of Reproduction and Fertility $\mathbf{8 0}$, $343-347$

Poulton, A.L. (1988) The proposed use of melatonin in controlled sheep breeding. Australian Journal of Biological Science 41, 87-96.

Poulton, A.L., English, J., Symons, A.M. \& Arendt, J. (1987) Changes in plasma concentrations of LH, FSH and prolactin in ewes receiving melatonin and short-photoperiod treatments to induce early onset of breeding activity. Journal of Endocrinology 112, 103111.

Rajkumar, R.R., Argo, C.M. \& Rodway, R.G. (1989) Fertility of ewes given either melatonin or progestogen sponges. Veterinary Record 124, 215-217.

Robinson, J.J., Wigzell, S., Aitken, R.P., Wallace, J.M., Ireland, S. \& Robertson, I.S. (1991) The modifying effects of melatonin, ram exposure and plane of nutrition on the onset of ovarian activity, ovulation rate and the endocrine status of ewes. Animal Reproduction Science 26, 73-91.

Robinson, J.J., Wigzell, S., Aitken, R.P., Wallace, J.M., Ireland, S. \& Robertson, I.S. (1992) Daily oral administration of melatonin from March onwards advances by 4 months the breeding season of ewes maintained under the ambient photoperiod at $57^{\circ} \mathrm{N}$. Animal Reproduction Science 27, 141-160.

Rodway, R.G., Robinson, J.J. \& Phillippo, M. (1983) Ovulation rate in induced oestrous cycles of anoestrous ewes given bromocriptine. Journal of Reproduction and Fertility 68, 265-267.

Ronayne, E., Jordan, B., Quirke, J.F. \& Roche, J.F. (1989) The effect of frequency of administration of melatonin on the time of onset of the breeding season in anoestrous ewes. Animal Reproduction Science 18, I 324.

Symons, A.M., Arendt, J. \& Laud, C.A. (1983) Melatonin feeding decreases prolactin levels in the ewe. Journal of Endocrinology 99, 41-46.

Wallace, J.M., Robinson, J.J., Wigzell, S. \& Aitken, R.P. (1988) Effect of melatonin on the peripheral concentrations of $\mathrm{LH}$ and progesterone after oestrus, and on conception rate in ewes. Journal of Endocrinology 119, $523-530$.

Wigzell, S., Robinson, J.J., Aitken, R.P. \& McKelvey, W.A.C. (1986) The effect of the oral administration of melatonin at two times of the year on ovarian activity in ewes. Animal Production 42, 448-449.

Received 21 May 1991 